\title{
Antimicrobial and anti-inflammatory activities of selected medicinal plants against pathogens causing sexually transmitted infections
}

\author{
Ndivhuho Patience Nthulane ${ }^{1}$, Salerwe Mosebi ${ }^{1}$, Thilivhali Emmanuel Tshikalange ${ }^{2}$, Monde Alfred Nyila ${ }^{1}$, Ledile \\ Thabitha Mankga ${ }^{*} \mathbb{D}$
}

${ }^{1}$ Department of Life and Consumer Sciences, University of South Africa, Private BagX06, Florida, 1710, South Africa

${ }^{2}$ Department of Plant and Soil Sciences, University of Pretoria, Private Bag X20, Hatfield 0028, South Africa

\section{A R T I C L E I N F O}

Article Type:

Original Article

Article History:

Received: 15 April 2019

Accepted: 2 October 2019

\section{Keywords:}

Antimicrobial activity

Anti-inflammation

HIV-1 reverse transcriptase

Sexually transmitted infections

Medicinal plants

Total phenolic content

\begin{abstract}
A B S T R A C T
Introduction: Worldwide, more than one million sexually transmitted infections (STIs) are acquired daily. The diversity and frequency of sexual infections caused by pathogenic microorganisms have increased thus becoming a major cause of illness and mortality amongst young adults. Medicinal plants have been good remedies for the treatment of STIs since ancient times. In this study, we evaluated antimicrobial, anti- Human immunodeficiency virus (HIV) and anti-inflammatory activities of five selected medicinal plants.

Methods: We determined the antimicrobial activities of plant extracts against the bacteria causing common STIs. Then, the anti-inflammatory activities were evaluated by measuring the inhibition of the pro-inflammatory enzyme, 15-lipoxygenase (15-LOX) and we further investigated the plants extracts of anti-HIV activities against the recombinant HIV-1 enzyme, reverse transcriptase.

Results: Methanol extract of Terminalia sericea and dichloromethane (DCM) extract of Bidens pilosa exhibited good activities against Neisseria gonorrhoeae and Gardnerella vaginalis. Ethyl acetate, dichloromethane and methanol extracts of Bidens pilosa exhibited good activities against Candida albicans. Ethyl acetate extract of $K$. africana and methanol extract of B. pilosa showed good anti-inflammatory activities. Ethyl acetate, DCM and methanol extracts of $T$. sericea exhibited promising anti-HIV-1 activities by inhibiting the reverse transcriptase whilst methanol extracts of $T$. dregeana showed low anti-HIV-1 activity.

Conclusion: These plants showed promising activity against the propagation of inflammation, displayed good antimicrobial activities against the bacteria causing STIs and could be used as potential leads and/or source for new drug candidates.
\end{abstract}

Implication for health policy/practice/research/medical education:

The studied plant extracts possess significant antimicrobial and anti-inflammatory activities and might contribute to the discovery of alternative antibiotics.

Please cite this paper as: Nthulane NP, Mosebi S, Tshikalange TE, Nyila MA, Mankga LT. Antimicrobial and anti-inflammatory activities of selected medicinal plants against pathogens causing sexually transmitted infections. J Herbmed Pharmacol. 2020;9(2):130-137. doi: 10.34172/jhp.2020.17.

\section{Introduction}

Sexually transmitted infections (STIs) among young adults in many rural communities have a profound impact on sexual and reproductive health and remain a major public health concern with more than one million STIs acquired daily, worldwide (1-3). The World Health Organization (WHO) identified Neisseria gonorrhoeae, Chlamydia trachomatis, Treponema pallidum and Trichomonas vaginalis as the pathogens that cause STIs. N. gonorrhoeae and T. pallidum, on the other hand, have been considered the most common causes of STIs in developing countries $(4,5)$.

The STIs caused by $N$. gonorrhoeae result in women infertility and pelvic inflammatory disease, while $T$. pallidum is considered the causative agent of syphilis that increases the risk of HIV acquisition and numerous hemolysin (6-10). Syphilis leads to approximately 305 000 fatal neonatal deaths in pregnant women every year, 
thus leaving around 200000 infants with increased risk of prematurity, low-birth-weight and congenital disease $(3,7)$.

Furthermore, infectious diseases caused by antimicrobial-resistant microbes are becoming a serious problem all over the world $(11,12)$. Inappropriate use of antibiotics has been attributed to the development of antibiotic resistance and the global emergence of multidrug resistant bacteria that gradually limit the efficacy of existing drugs resulting in treatment failure (13). Molecular mechanisms responsible for the development of drug resistance are a subject of great interest and have also been highlighted in various reports revealing clinical resistance to antifungal agents (14).

Medicinal plants have been touted as the possible sources of new classes of antimicrobial agents with novel modes of action and represent a viable alternative to treat and/or cure the infections that result from the resistant microbes. Medicinal plants have been used as remedies for the treatment of STIs since ancient times (15). The WHO reported that about $80 \%$ of the population in developing countries are dependent on medicinal plants as the primary source of health care (16). Accordingly, medicinal plants have been used to treat different ailments and they are also regarded as remedies with several advantages such as fewer side effects, low cost and are readily available (1719). Plant extracts constituents of bioactive secondary metabolites such as flavonoid, alkaloids, tannins, terpenoids and phenolics act synergistically to combat the microbial growth (20). The validation and approval of medicinal plants for the treatment of diseases caused by pathogens could be of great value to most people in rural communities who have limited access to vital, life-saving and often costly modern medicine (21-23). Therefore, in this study, we aimed to evaluate the antimicrobial and anti-inflammatory activities of selected medicinal plants against bacteria or pathogens that cause STIs. Firstly, we evaluated the antimicrobial activity using different solvents. We, then determined the anti-inflammatory activities using the plant extracts on 15-lipoxygenase (15LOX) enzyme. Lastly, we determined the total phenolic content and the inhibitory activity of plant extracts on HIV-1 reverse transcriptase (RT) enzyme.

\section{Materials and Methods}

Plants materials

Medicinal plants were selected based on their ethnomedicinal uses in the treatment of STIs as previously described (24-31). Plant materials were collected from the Walter Sisulu National Botanical Garden in Roodepoort, Gauteng province (South Africa). A voucher specimen of each plant were also prepared (Table S1).

\section{Preparation of plant extracts}

Plant materials were air-dried and ground into a fine powder. Different powdered plant materials were weighed and dissolved in dichloromethane (DCM), ethyl acetate and methanol, respectively. The honey jars were vigorously shaken for 24 hours using a shaker at room temperature. The extracts were filtered using Whatman filter paper and the remaining plant materials were discarded. The extracts were then transferred into pre-weighed labeled bottles and placed in the fume hood to evaporate the remaining solvents.

\section{Microbial strains}

The following microorganisms were used in this study: Neisseriagonorrhoeae (ATCC 49226), Gardnerella vaginalis (ATCC14018) and Candida albicans (ATCC10231). All pathogens were cultured in a sterile fume hood. $N$. gonorrhoea was inoculated in Mueller-Hinton broth and incubated at $37^{\circ} \mathrm{C}$ for 24 hours in a humid environment enriched $\mathrm{CO}_{2}$. G. vaginalis was inoculated in brain and heart infusion broth and incubated at $37^{\circ} \mathrm{C}$ for 24 hours. C. albicans was inoculated in tryptone soya broth and incubated at $37^{\circ} \mathrm{C}$ for 24 hours.

\section{Antimicrobial activity}

Antimicrobial activity was determined using broth microdilution method in 96-well plate as previously described (32). Briefly, $50 \mathrm{mg}$ of each plant extract was weighed in $2 \mathrm{~mL}$ microcentrifuge tubes and each extract was dissolved in $1 \mathrm{~mL}$ of $10 \%$ dimethyl sulfoxide (DMSO). Microorganisms were inoculated in sterile broth and prepared to a density of $1.5 \times 10^{8}$ colony forming units (CFU) per $\mathrm{mL}$, corresponding with the $0.5 \mathrm{McF}$ arland standard. Then, a $100 \mu \mathrm{L}$ of broth was added to the wells of the plate and a $100 \mu \mathrm{L}$ of each dissolved plant extract $(50 \mathrm{mg} / \mathrm{mL})$ was added to the first well in triplicate and serially diluted. Later, a $100 \mu \mathrm{L}$ of pathogen suspension was added to each well except control wells, ciprofloxacin that was used as a control compound for all the extracts, and $10 \%$ of DMSO used as a negative control. The plates were incubated at $37^{\circ} \mathrm{C}$ for 24 hours. Finally, the results were read based on colour change after adding $40 \mu \mathrm{L}$ of 0.2 $\mathrm{mg} / \mathrm{mL}$ Presto Blue dye. A pink colour change indicated microbial growth whereas clear wells indicated inhibition of growth by test plant extract. The lowest concentration that showed no visible pathogen growth was recorded as the MIC for each microorganism.

\section{Anti-inflammatory activity}

The anti-inflammatory activity of the plant extracts was performed as previously described (33). Briefly, plant extracts were prepared at $10 \mathrm{mg} / \mathrm{mL}$ in DMSO and the 15-LOX enzyme was prepared on ice up to the final concentration of 200 units $/ \mathrm{mL}$. A volume of $12.5 \mu \mathrm{L}$ of each plant sample and controls were then added to 487.5 $\mu \mathrm{L}$ of 15 -LOX in 96-well microtiter plate and incubated for 5 minutes at room temperature. After incubation $500 \mu \mathrm{L}$ of substrate solution was added to 96 well microtiter plate and incubated for 5 minutes at room temperature. After 
incubation, the absorbance was measured at $234 \mathrm{~nm}$ using the microtiter plate reader. Quercetin $(1 \mathrm{mg} / \mathrm{mL})$ was used as a control compound and DMSO as a negative control. The results were expressed as mean \pm standard error of mean obtained from two independent experiments.

HIV-1 reverse transcriptase inhibition studies

The activity of plant extracts on reverse transcriptase activity was determined using the HIV-1 RT colorimetric ELISA kit (Roche). Firstly, all plant materials were weighed up to $3 \mathrm{mg}$ and dissolved in $1 \mathrm{~mL}$ DMSO to make a final concentration of $3 \mathrm{mg} / \mathrm{mL}$ stock solution. A stock solution of $10 \mu \mathrm{L}$ was added to $90 \mu \mathrm{L}$ of lysis buffer to make a final concentration of $0.3 \mathrm{mg} / \mathrm{mL}$. The RT enzyme was prepared to a stock solution of $0.764 \mathrm{mg} / \mathrm{mL}$ and $0.327 \mu \mathrm{L}$ was added to $1000 \mu \mathrm{L}$. Lastly, $20 \mu \mathrm{L}$ of enzyme, diluted extracts and reaction mixture $(10 \mu \mathrm{M}$ dUTP/dTTP, template/primer hybrid) were added together into wells of the plate. Then, doxorubicin at various concentrations $(25 \mu \mathrm{g} / \mathrm{mL}, 50 \mu \mathrm{g} /$ $\mathrm{mL}$ and $100 \mu \mathrm{g} / \mathrm{mL}$ ) dissolved in 10\% DMSO was used as a control compound, whilst lysis buffer with reaction mixture was used as a negative control. The plates were incubated for 1 hour at $37^{\circ} \mathrm{C}$. After incubation, the wells were rinsed three times with $200 \mu \mathrm{L}$ of washing buffer per well. After washing, $200 \mu \mathrm{L}$ of anti-digoxigenin-peroxidase (DIG-POD) solution, prepared to a final concentration of $200 \mathrm{mU} / \mathrm{mL}$, was added to each well, covered with foil and incubated for 1 hour at $37^{\circ} \mathrm{C}$. After incubation, the solutions were removed from the plate wells and washed three times with $200 \mu \mathrm{L}$ of washing buffer. Thereafter, 200 $\mu \mathrm{L}$ of 2,2-azino-bis(3-ethylbenzothiazoline-6-sulphonic acid) substrate solution was added to each well and allowed to stand for 10 minutes. The absorbance was then measured on a microtiter plate reader at a wavelength of
$405 \mathrm{~nm}$ with a reference wavelength of $490 \mathrm{~nm}$. The assay was performed in triplicate and percentage inhibition calculated using the following formula:

$\%$ Inhibition $=\{1-(\mathrm{OD}$ sample/OD negative control $)\} \times 100$ (1)

where OD is the optical density of the sample at $405 \mathrm{~nm}$.

Determination of total phenolic content

The amount of total phenolic content in plant samples was determined according to the Folin-Ciocalteu method as previously described but with slight modifications (34). In brief, $25 \mu \mathrm{L}$ of the extract was treated with $250 \mu \mathrm{L}$ of FolicCiocalteu reagent for 5 minutes. The reaction was stopped by adding $750 \mu \mathrm{L}$ of $20 \%$ anhydrous sodium carbonate. The volume was made up to $5 \mathrm{~mL}$ with distilled water and incubated at room temperature for 2 hours. After incubation, the absorbance was read at $760 \mathrm{~nm}$ using the spectrophotometer. The phenolic content was determined from the standard curve of different concentrations of gallic acid and results were expressed as $\mathrm{mg} / \mathrm{g}$ gallic acid equivalent (GAE).

\section{Results}

Antimicrobial activity

The antimicrobial activity results are expressed in minimum inhibitory concentration (MIC) values shown in Table 1. The methanol extract of Terminalia sericea and DCM extract of Bidens pilosa showed good activity with MIC value of $0.8 \mathrm{mg} / \mathrm{mL}$ (Table 1). Ethyl acetate and DCM extracts of $K$. africana and DCM extract of T. dregeana displayed some antibacterial activity with MIC of $8.1 \mathrm{mg} /$ mL. Methanol extract of K. africana, C. papaya and B. pilosa gave similar antibacterial activities with MIC value

Table 1. The minimum inhibitory concentration (MIC) values of plant species tested against different microorganisms

\begin{tabular}{|c|c|c|c|c|}
\hline Sample & Extraction solvent & Neisseria gonorrhoeae & Gardnerella vaginalis & Candida albicans \\
\hline Ciprofloxacin & & $<0.2$ & 3.1 & $<0.2$ \\
\hline \multirow{3}{*}{ K. africana } & ET & 8.1 & 12.5 & 8.1 \\
\hline & DCM & 8.1 & 6.3 & 8.1 \\
\hline & $M$ & 6.3 & 6.3 & 8.1 \\
\hline \multirow{3}{*}{ T. sericea } & ET & 3.1 & 3.1 & 6.3 \\
\hline & DCM & 3.1 & 3.1 & 6.3 \\
\hline & $M$ & 0.8 & 1.6 & 6.3 \\
\hline \multirow{3}{*}{ C. papaya } & ET & 6.3 & $>12.5$ & 1.6 \\
\hline & DCM & 3.1 & 6.3 & 1.6 \\
\hline & M & 6.3 & 6.3 & 1.6 \\
\hline \multirow{3}{*}{ B. pilosa } & ET & 6.3 & 3.1 & 0.4 \\
\hline & DCM & 0.8 & 3.1 & 0.4 \\
\hline & $M$ & 3.1 & 3.1 & 0.4 \\
\hline \multirow{3}{*}{ T. dregeana } & ET & 3.1 & 12.5 & 6.3 \\
\hline & DCM & 8.1 & 6.3 & 12.5 \\
\hline & M & 3.1 & 6.3 & 3.1 \\
\hline
\end{tabular}

ET, ethyl acetate; DCM, dichloromethane; M, methanol. 
of $6.3 \mathrm{mg} / \mathrm{mL}$ (Table 1 ).

Methanol extract of T. sericea was tested on Gardnerella vaginalis and showed good activity with the MIC value of $1.6 \mathrm{mg} / \mathrm{mL}$. The DCM extracts of C. papaya, T. dregeana and $K$. africana showed some activity with MIC of about $1.6 \mathrm{mg} / \mathrm{mL}$. Ethyl acetate extract of C. papaya indicated no activity with the MIC value higher than the tested concentrations $>12.5 \mathrm{mg} / \mathrm{mL}$.

Ethyl acetate, DCM and methanol leave extracts of $B$. pilosa showed best antimicrobial activity for $C$. albicans with an MIC value of $0.4 \mathrm{mg} / \mathrm{mL}$. Meanwhile, ethyl acetate, DCM and methanol leaves extracts of $K$. africana and $T$. sericea indicated some antifungal activity with the MIC value of $8.1 \mathrm{mg} / \mathrm{mL}$ and $6.3 \mathrm{mg} / \mathrm{mL}$, respectively (Figure 1).

Anti-inflammatory activity

The ethyl acetate and DCM extracts of $K$. africana and methanol extract of $B$. pilosa contained compounds with higher activity compared to quercetin (control compound) whereas all extracts of $T$. sericea showed low inhibitory activity (Table 2).

HIV-1 reverse transcriptase inhibition

The percentage inhibition activity of plant extracts against RT enzyme are shown in Figure 1. Inhibitory activities of the plant extracts against HIV-1 RT ranged from 15.79\% to $80.16 \%$ inhibition at a final concentration of $100 \mu \mathrm{g} /$ $\mathrm{mL}$. The results were compared to the control compound, doxorubicin, which has been shown and validated to inhibit the RT enzyme (Figure 1). Ethyl acetate, DCM and methanol leaf extracts of $T$. sericea exhibited high inhibition activity (>70\%).

Ethyl acetate and DCM extracts of T. dregeana leaf extract showed moderate inhibitory activity while
Table 2. The anti-inflammatory activity of medicinal plants. Percentage inhibition of 15-lipoxygenase (15-LOX) result

\begin{tabular}{|c|c|c|}
\hline Sample & Extraction solvent & Inhibition \% \\
\hline Quercetin & - & $49.61 \pm 12.5$ \\
\hline \multirow{3}{*}{ K. africana } & ET & $60.49 \pm 10.23$ \\
\hline & DCM & $45.55 \pm 11.94$ \\
\hline & M & $5.79 \pm 1.62$ \\
\hline \multirow[t]{3}{*}{ T. sericea } & ET & $33.04 \pm 1.23$ \\
\hline & DCM & $14.40 \pm 5.54$ \\
\hline & M & $21.71 \pm 5.71$ \\
\hline \multirow{3}{*}{ C. papaya } & ET & $18.74 \pm 1.84$ \\
\hline & DCM & $33.46 \pm 3.22$ \\
\hline & $M$ & $70.94 \pm 3.11$ \\
\hline \multirow{3}{*}{ B. pilosa } & ET & $6.69 \pm 1.00$ \\
\hline & DCM & $25.46 \pm 0.62$ \\
\hline & $M$ & $58.47 \pm 3.83$ \\
\hline \multirow{3}{*}{ T. dregeana } & ET & $21.37 \pm 1.08$ \\
\hline & DCM & $28.49 \pm 1.90$ \\
\hline & $\mathrm{M}$ & $70.06 \pm 2.53$ \\
\hline
\end{tabular}

methanol extract of T. dregeana indicated low inhibitory activity (Figure 1). Ethyl acetate and DCM extracts of C. papaya showed moderate inhibitory activity whilst methanol extract of $C$. papaya had no inhibitory activity. Ethyl acetate extract of $B$. pilosa displayed high inhibitory activity with an inhibition percentage of $80 \%$. DCM and methanol extracts of $B$. pilosa yielded moderate inhibitory activity of $65 \%$ and $55 \%$, respectively. Inhibitory activities of ethyl acetate and methanol extracts of $K$. africana were moderate at $65 \%$ and $60 \%$, respectively whilst DCM extract of $K$. africana had the highest inhibitory activity of $70 \%$ (Figure 1).

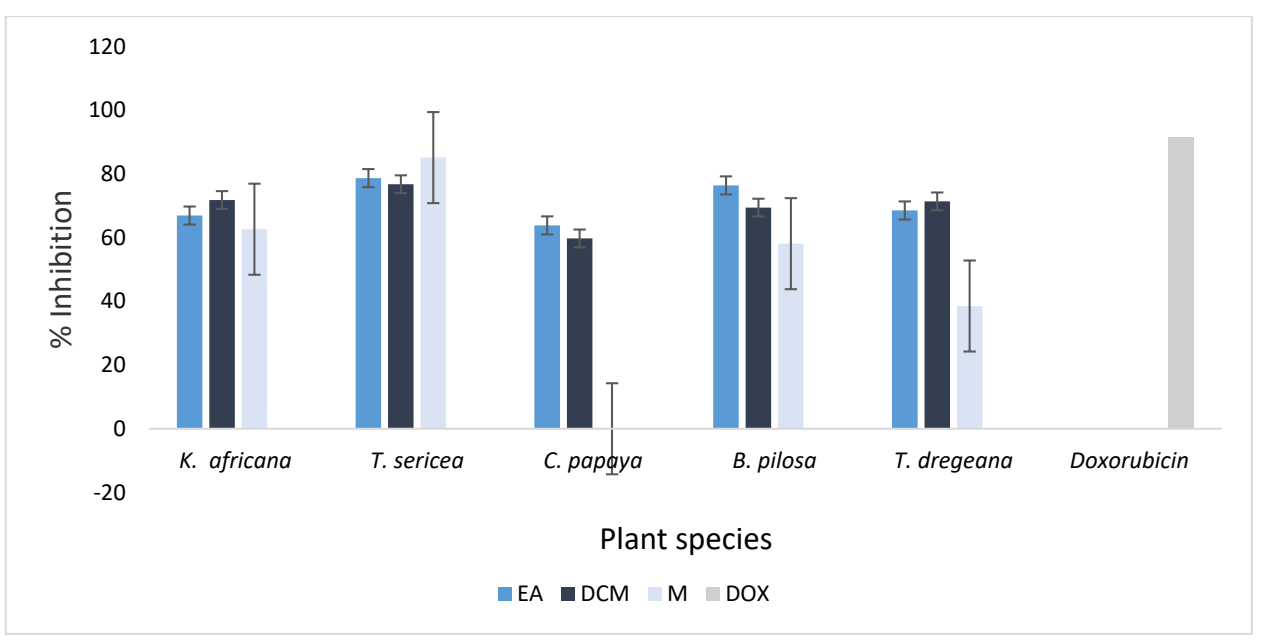

Figure 1. The activity of medicinal plant extracts on recombinant HIV-1 reverse transcriptase (RT) using HIV-1 RT colorimetric ELISA assay. The RT inhibitory activity of tested samples is expressed as percentage (\%) inhibition. EA, ethyl acetate; DCM, dichloromethane; M, methanol; DOX, doxorubicin. The difference between the control (untreated) and the treated samples was determined by one-way ANOVA test (Bonferroni multiple comparison test). $P$ $<0.05$ compared to control group. 
Total phenolic content

The total phenolic contents of the extracts were examined using the Folin-Ciocalteu method and reported as a gallic acid equivalent (mg/g GAE) (Figure 2). The highest number of phenolic compounds were obtained from methanol extract of $T$. sericea at $270 \mathrm{mg} / \mathrm{g}$ GAE followed by ethyl acetate extract of $C$. papaya and methanol extract of $B$. pilosa with the total phenolic content of $130 \mathrm{mg} / \mathrm{g}$ GAE. Ethyl acetate extract of $K$. africana and DCM extract of $T$. dregeana had the lowest amount of phenolic compounds at $20 \mathrm{mg} / \mathrm{g}$ GAE. Interestingly, no phenolic compounds were detected in the DCM extract of both $B$. pilosa and K. africana and methanol extract of K. africana.

\section{Discussion}

Antimicrobial activity

Medicinal plants have been used as the possible source of new classes of antimicrobial agents with novel modes of action and represent a viable alternative to treat and/ or cure the infections that result from resistant microbes. They have been used as remedies for the treatment of STIs since ancient times (15) and some medicinal plants have exhibited poorer or noteworthy antimicrobial efficacies against the pathogens associated with STI's. For example, in this study, the methanol extract of T. sericea and DCM extracts of $B$. pilosa showed good activities with the MIC value of $0.8 \mathrm{mg} / \mathrm{mL}$. Also, the plant extracts of T. sericea have previously exhibited antimicrobial activity with the MIC value of $1 \mathrm{mg} / \mathrm{mL}$ while its roots tested against $N$. gonorrhoeae indicated the MIC value of $1.6 \mathrm{mg} / \mathrm{mL}$ $(35,36)$. But, Mamba et al $(36)$, indicated T. sericea having the least activity against $G$. vaginalis with the MIC value of $>12.5 \mathrm{mg} / \mathrm{mL}$ in their research. The differences in MIC value results obtained in many studies are usually associated with the area of collection, environmental conditions, the season of collection and the age of the plant (37). However, van Vuuren (35) tested T. sericea against anti-microial activity and the results of aqueous extract correlated well with our findings. Furthermore, Naidoo and colleagues' study using a combination of plant extracts from C. papaya, T. dregeana, K. africana and $B$. pilosa demonstrated moderate antimicrobial activities that also correlated well with our findings in terms of organic extract (38). C. papaya has been shown to be efficacious in the treatment of STIs and has subsequently displayed good wound healing activities in the past (39). Steenkamp et al (40) tested the roots of T. sericea against C. albicans and showed inhibition of STIs bacteria. Similarly, Moshi and Mbwambo (41) tested the inhibition of C. albicans growth using methanol extracts of T. sericea and their results also indicated a notable inhibition of $C$. albicans growth that correlates with the findings of this study.

Anti-inflammatory activity

Inflammation plays an important role in the resolution of many diseases as well as the STIs (36) and the plant extracts that have anti-inflammatory activities usually inhibit the cyclooxygenase (COX) and/or LOX activity (36). Such plants usually have active therapeutic effects that promote healing and repair of tissue cells (42). T. sericea contains a phenolic anti-inflammatory compound, triterpenoid saponin, which can inhibit the COX-2 and 5-LOX enzymes (43). The observed anti-inflammatory activity may be due to the overall effects of plants constituents or compounds having similar action to the anti-inflammatory agent and non-steroidal anti-inflammatory drugs (48). However, all the tested leave extracts of T. sericea exhibited low 15LOX inhibitory activities. As a result, T. sericea might have compounds that have anti-inflammatory activities that are lower than that of quercetin. Also, the low inhibition

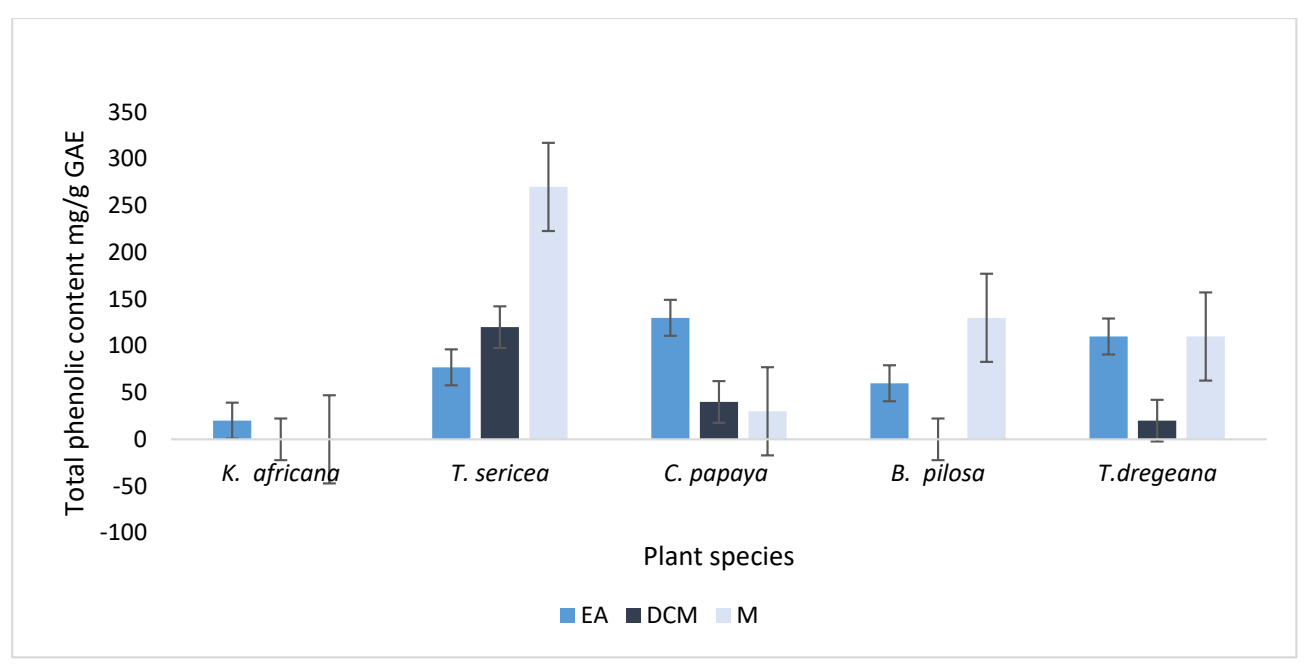

Figure 2. Total phenolic content of medicinal plants tested with the Folin-Ciocalteu method and expressed as mg/g gallic acid equivalents (GAE). EA, ethyl acetate; DCM, dichloromethane; M, methanol; DOX, doxorubicin. The difference between the control (untreated) and the treated samples was determined by one-way ANOVA test (Bonferroni multiple comparison test). ${ }^{*} P<0.05$ compared to control group. 
obtained could be due to impurities or low concentration of active compounds in the crude extract (44).

HIV-1 reverse transcriptase inhibition

People infected with HIV depend on antiretroviral drugs which include protease, reverse transcriptase and integrase inhibitors to prolong their lives. Nonetheless, antiretroviral drugs have disadvantages such as high costs, high toxicity profiles and development of resistance after long-term use (45). In this study, the plant extract of $T$. sericea showed the highest inhibitory activity of $102.8 \%$. Similarly, Krishnaveni (46) and Mamba et al (36) used T. sericea extract, which inhibited both HIV-1 RT and COX2 enzyme and this result concurs with those published, previously. Several plant extracts showed good inhibitory activities against HIV-1 RT and to our knowledge, there are no previous studies reporting the HIV-1 RT inhibition of B. pilosa, C. papaya, K. africana and T. dregeana.

Total phenolic content

Plant phenolic compounds have shown various medicinal properties such as anti-inflammatory, anti-diabetic, antimicrobial, anti-carcinogenic and antiviral activities (47). Due to these pharmacological properties, plant phenolic compounds have gained increasing attention in both modern and traditional medicine as a possible source of new therapeutics. In this study, methanol extract of $T$. sericea with lower crude extract yield of $2.19 \%$ contained relatively high amounts of phenolics content which could be responsible for antimicrobial and anti-inflammatory activity observed. Anokwuru et al (49) indicated that methanol extract of $T$. sericea had the highest total phenolic content of $440 \mathrm{mg} / \mathrm{g}$ GAE. On the other hand, Singh et al (50) reported the total phenolic content of methanol extract from $B$. pilosa to be about $72 \mathrm{mg} / \mathrm{g}$ GAE. In addition, leaves of $C$. papaya were shown to have high total phenolic content that might provide the best sources of dietary antioxidants (51).

\section{Conclusion}

After evaluation of five selected medicinal plants against the pathogens causing STIs, some plants (T. sericea and B. pilosa) were shown to have good antimicrobial activity and had the potential to be used as alternative therapeutic options for the treatment of STIs. Additionally, some plants had promising activities against the propagation of inflammation. Accordingly, for a medicinal plant to be considered the candidate plant with good antimicrobial activity, it should contain the lowest MIC value in each microorganism tested. The plant extracts, which can inhibit the pro-inflammatory activities of the 15-LOX enzyme, could also be used for the discovery and development of new and novel anti-inflammatory compounds. Further characterization studies such as isolation, identification, solubility, pharmacokinetics and toxicity profiles of bioactive compounds in these plants should be conducted to explore other pharmacological properties.

\section{Acknowledgements}

The authors would like to acknowledge the University of South Africa for financial assistance. The University of South Africa and the University of Pretoria for laboratory equipments.

\section{Author's contributions}

TET, MAN and LTM designed the project. NPN, MAN and LTM identified, collected and pressed plant material. NPN and TET carried out the laboratory work. NPN, LTM and SM analyzed the results. LTM, SM and NPN wrote the manuscript. All authors read the final version and confirmed its publication.

\section{Conflict of interests}

No conflict of interest.

\section{Ethics considerations}

The protocol was approved by the University of South Africa Research Committee with the ethics number: 2017/ CAES/063.

\section{Funding/Support}

The University of South Africa funded this project for data collection and laboratory reagents (Departmental funding: grant code RC201500). University of Pretoria provided the laboratory equipment and analysis of the data.

\section{Supplementary Materials}

Supplementary file 1 contains Table S1.

\section{References}

1. Torrone EA, Morrison CS, Chen PL, Kwok C, Francis SC, Hayes RJ, et al. Prevalence of sexually transmitted infections and bacterial vaginosis among women in sub-Saharan Africa: An individual participant data meta-analysis of 18 HIV prevention studies. PLoS Med. 2018;15(2):e1002511. doi: 10.1371/journal.pmed.1002511.

2. Tshikalange TE, Meyer JJ, Hussein AA. Antimicrobial activity, toxicity and the isolation of a bioactive compound from plants used to treat sexually transmitted diseases. J Ethnopharmacol. 2005;96(3):515-9. doi: 10.1016/j. jep.2004.09.057.

3. World Health Organization (WHO). Management of patients with sexually transmitted diseases. WHO Technical Report Series. 2018.

4. World Health Organization (WHO). Management of patients with sexually transmitted diseases. WHO Technical Report Series. 2017.

5. World Health Organization (WHO). Management of patients with sexually transmitted diseases. WHO Technical Report Series. 2016.

6. Buwa LV, van Staden J. Antibacterial and antifungal activity 
of traditional medicinal plants used against venereal diseases in South Africa. J Ethnopharmacol. 2006;103(1):139-42. doi: 10.1016/j.jep.2005.09.020.

7. Newman L, Kamb M, Hawkes S, Gomez G, Say L, Seuc A, et al. Global estimates of syphilis in pregnancy and associated adverse outcomes: analysis of multinational antenatal surveillance data. PLoS Med. 2013;10(2):e1001396. doi: 10.1371/journal.pmed.1001396.

8. Fraser CM, Norris SJ, Weinstock GM, White O, Sutton GG, Dodson R, et al. Complete genome sequence of Treponema pallidum, the syphilis spirochete. Science. 1998;281(5375):375-88. doi: 10.1126/science.281.5375.375.

9. Hazlett KR, Cox DL, Decaffmeyer M, Bennett MP, Desrosiers DC, La Vake CJ, et al. TP0453, a concealed outer membrane protein of Treponema pallidum, enhances membrane permeability. J Bacteriol. 2005;187(18):6499508. doi: 10.1128/jb.187.18.6499-6508.2005.

10. Peeling RW, Hook EW 3rd. The pathogenesis of syphilis: the Great Mimicker, revisited. J Pathol. 2006;208(2):224-32. doi: 10.1002/path.1903.

11. Srivastava J, Chandra H, Nautiyal AR, Kalra SJ. Antimicrobial resistance (AMR) and plant-derived antimicrobials (PDAms) as an alternative drug line to control infections. 3 Biotech. 2014;4(5):451-60. doi: 10.1007/s13205-013-0180-y.

12. Gyles $C$. The growing problem of antimicrobial resistance. Can Vet J. 2011;52(8):817-20.

13. Djeussi DE, Noumedem JA, Seukep JA, Fankam AG, Voukeng IK, Tankeo SB, et al. Antibacterial activities of selected edible plants extracts against multidrug-resistant Gram-negative bacteria. BMC Complement Altern Med. 2013;13:164. doi: 10.1186/1472-6882-13-164.

14. Yang YL, Lo HJ. Mechanisms of antifungal agent resistance. J Microbiol Immunol Infect. 2001;34(2):79-86.

15. Ndubani P, Höjer B. Traditional healers and the treatment of sexually transmitted illnesses in rural Zambia. J Ethnopharmacol. 1999;67(1):15-25. doi: 10.1016/s03788741(99)00075-6.

16. Gurib-Fakim A. Medicinal plants: traditions of yesterday and drugs of tomorrow. Mol Aspects Med. 2006;27(1):1-93. doi: 10.1016/j.mam.2005.07.008.

17. van der Watt E, Pretorius JC. Purification and identification of active antibacterial components in Carpobrotus edulis L. J Ethnopharmacol. 2001;76(1):87-91. doi: 10.1016/s03788741(01)00197-0.

18. Mathur A, Singh R, Yousuf S, Bhardwaj A, Verma SK, Babu $\mathrm{P}$, et al. Antifungal activity of some plant extracts against Clinical Pathogens. Adv Appl Sci Res. 2011;2(2):260-4.

19. Prince L, Prabakaran P. Antifungal activity of medicinal plants against plant pathogenic fungus Colletotrichum falcatum. Asian J Plant Sci Res. 2011;1(1):84-7.

20. Cowan MM. Plant products as antimicrobial agents. Clin Microbiol Rev. 1999;12(4):564-82.

21. Gessler MC, Nkunya MH, Mwasumbi LB, Heinrich M, Tanner M. Screening Tanzanian medicinal plants for antimalarial activity. Acta Trop. 1994;56(1):65-77. doi: 10.1016/0001-706x(94)90041-8.

22. Jamison DT, Breman JG, Measham AR, Alleyne G, Claeson M, Evans DB, et al. Disease Control Priorities in Developing Countries. 2nd ed. In: Foster S, Laing R, Melgaard B,
Zaffran M, eds. Ensuring Supplies of Appropriate Drugs and Vaccines. Washington DC: World Bank; 2006.

23. Patwardhan B. Traditional Medicine: Modern Approach for Affordable Global Health. Geneva: World Health Organization; 2005. p. 1-172.

24. Watt JM, Breyer-Brandwijk MG. The Medicinal and Poisonous Plants of Southern and Eastern Africa. 2nd ed. Edinburgh: Livingstone; 1962.

25. Arnold HJ, Gulumian M. Pharmacopoeia of traditional medicine in Venda. J Ethnopharmacol. 1984;12(1):35-74. doi: 10.1016/0378-8741(84)90086-2.

26. Abbiw DK. Useful plants of Ghana. West African uses of wild and cultivated plants. London and Royal Botanic Gardens, Kew: Intermediate Technology Publications; 1990.

27. Mabogo DEN. The Ethnobotany of the Vhavenda. South Africa: University of Pretoria; 1990.

28. Hutchings A, Scott AH, Lewis G, Cunningham A. Zulu Medicinal Plants: An Inventory. Pietermaritzburg, South Africa: University of Natal Press; 1996.

29. Chomnawang MT, Trinapakul C, Gritsanapan W. In vitro antigonococcal activity of Coscinium fenestratum stem extract. J Ethnopharmacol. 2009;122(3):445-9. doi: 10.1016/j.jep.2009.01.036.

30. Van Wyk BE, Van Oudtshoorn B, Gericke N. Medicinal Plants of South Africa. South Africa: Briza; 2009.

31. Alabi OA, Haruna MT, Anokwuru CP, Jagede T, Abia H, Okegbe VU, et al. Comparative studies on antimicrobial properties of extracts of fresh and dried leaves of Carica papaya (L) on clinical bacterial and fungal isolates. Adv Appl Sci Res. 2012;3(5):3107-14.

32. Eloff JN. A sensitive and quick microplate method to determine the minimal inhibitory concentration of plant extracts for bacteria. Planta Med. 1998;64(8):711-3. doi: 10.1055/s-2006-957563.

33. Adebayo SA, Dzoyem JP, Shai LJ, Eloff JN. The antiinflammatory and antioxidant activity of 25 plant species used traditionally to treat pain in southern African. BMC Complement Altern Med. 2015;15:159. doi: 10.1186/ s12906-015-0669-5.

34. Makkar HPS. Quantification of Tannins in Tree Foliage: A laboratory manual for the FAO/IAEA Co-ordinated Research Project on 'Use of Nuclear and Related Techniques to Develop Simple Tannin Assays for Predicting and Improving the Safety and Efficiency of Feeding Ruminants on Tanniniferous Tree Foliage. Vienna: Joint FAO/IAEA Division of Nuclear Techniques in Food and Agriculture; 1999. p. 1-29.

35. van Vuuren SF, Naidoo D. An antimicrobial investigation of plants used traditionally in southern Africa to treat sexually transmitted infections. J Ethnopharmacol. 2010;130(3):5528. doi: 10.1016/j.jep.2010.05.045.

36. Mamba P, Adeboyo SA, Tshikalange TE. Anti-microbial, anti-inflammatory and HIV-1 reverse transcriptase activity of selected South African plants used to treat sexually transmitted diseases. Int J Pharmacogn Phytochem Res. 2016;8(11):1870-6.

37. Mongalo NI. Peltophorum africanum Sond [Mosetlha]: a review of its ethnomedicinal uses, toxicology, phytochemistry and pharmacological activities. J Med Plants 
Res. 2013;7(48):3484-91. doi: 10.5897/JMPR2013.5302.

38. Naidoo D, van Vuuren SF, van Zyl RL, de Wet H. Plants traditionally used individually and in combination to treat sexually transmitted infections in northern Maputaland, South Africa: antimicrobial activity and cytotoxicity. J Ethnopharmacol. 2013;149(3):656-67. doi: 10.1016/j. jep.2013.07.018.

39. Gurung S, Skalko-Basnet N. Wound healing properties of Carica papaya latex: in vivo evaluation in mice burn model. J Ethnopharmacol. 2009;121(2):338-41. doi: 10.1016/j. jep.2008.10.030.

40. Steenkamp V, Fernandes AC, Van Rensburg CEJ. Screening of Venda medicinal plants for antifungal activity against Candida albicans. S Afr J Bot. 2007;73(2):256-8. doi: 10.1016/j.sajb.2006.11.003.

41. Moshi MJ, MbwamboZH. Some pharmacological properties of extracts of Terminalia sericea roots. J Ethnopharmacol. 2005;97(1):43-7. doi: 10.1016/j.jep.2004.09.056.

42. Ncube B, Finnie JF, Van Staden J. In vitro antimicrobial synergism within plant extract combinations from three South African medicinal bulbs. J Ethnopharmacol. 2012;139(1):81-9. doi: 10.1016/j.jep.2011.10.025.

43. Cock IE. The medicinal properties and phytochemistry of plants of the genus Terminalia (Combretaceae). Inflammopharmacology. 2015;23(5):203-29. doi: 10.1007/ s10787-015-0246-z.

44. Mulaudzi RB, Ndhlala AR, Kulkarni MG, Finnie JF, Van Staden J. Anti-inflammatory and mutagenic evaluation of medicinal plants used by Venda people against venereal and related diseases. J Ethnopharmacol. 2013;146(1):173-9. doi: 10.1016/j.jep.2012.12.026.

45. Klos M, van de Venter M, Milne PJ, Traore HN, Meyer D, Oosthuizen V. In vitro anti-HIV activity of five selected South African medicinal plant extracts. J Ethnopharmacol. 2009;124(2):182-8. doi: 10.1016/j.jep.2009.04.043.

46. Krishnaveni M. Medicinal plants- A boon for HIV/AIDS. J Pharm Res. 2012;5(12):5367-79.

47. Cushnie TP, Lamb AJ. Antimicrobial activity of flavonoids. Int J Antimicrob Agents. 2005;26(5):343-56. doi: 10.1016/j. ijantimicag.2005.09.002.

48. Adedapo AA, Sofidiya MO, Masika PJ, Afolayan AJ. Antiinflammatory and analgesic activities of the aqueous extract of Acacia karroo stem bark in experimental animals. Basic Clin Pharmacol Toxicol. 2008;103(5):397-400. doi: 10.1111/j.1742-7843.2008.00317.x.

49. Anokwuru CP, Ramaile IDI, Bessong P. Phenolic content distribution and antioxidant activities of Terminalia sericea Burch. Afr J Tradit Complement Altern Med. 2005;12(4):217. doi: 10.4314/ajtcam.v12i4.4.

50. Singh G, Passsari AK, Singh P, Leo VV, Subbarayan S, Kumar B, et al. Pharmacological potential of Bidens pilosa L. and determination of bioactive compounds using UHPLCQqQLIT-MS/MS and GC/MS. BMC Complement Altern Med. 2017;17(1):492. doi: 10.1186/s12906-017-2000-0.

51. Nariya A, Jhala D. Pharmacognostic study of Carica papaya leaf extract as inhibitors of reactive oxygen species. Int Res J Pharm. 2017;8(3):13-7. doi: 10.7897/2230-8407.080328. 